\title{
Self-Controlling Rig for Jaw Crusher Assembly
}

\author{
Saurabh Jadhav ${ }^{1}$, Anup Pawar ${ }^{2}$
}

\begin{abstract}
The aim of the work is to develop a method for easy assembly of the bearing in the housing by standardized way. The assembly of bearing should take place on the atomized set up. Based on this method a assembly setup was constructed which enables to assembly of the shaft with bearing of different models of jaw crusher. First tests were done with manual alignment and it shows that with proper alignment shaft assembly is very easy operation and also safe. Results of those tests show that the developed system provides as good or better results than the manual assembly method by placing on wooden block and aligns by using jacking. The alignment process itself runs automatically. The results are reliable, independent form the user and reproducible. Furthermore the whole assembling of the bearings on a shaft should be automated without to interrupt the process of mounting in order to fatigue for assembler and misalignment in bearing . the assembly of the shaft with bearing in the swing jaw is very critical as well important so it needs attention because any mistake can cause the failuare of the system which result in breakdown and also the bearing failure which is the highest cost element . so the propose system eliminate the manual alignment and the safety issue and also the problem of incorrect assembly of the bearing in jaw by aligning the jaw bore and then only pushing the shaft in straight line so there is no shock load on the bearing which may result the misplacement and misalignment of thr roller in the bearing housing
\end{abstract}

Keywords: Jaw crusher, Bearing assembly, Automation, Safety.

\section{INTRODUCTION}

According to the standard procedure the swing jaw is first painted then allowed to dry. Further the eccentric shaft assembly is assembled in the jaw, but before that the jaw is place on the wooden blocks.

As there is a very fine clearance available between the outer race of the bearing and the jaw bore it is necessary that the alignment of their axis is perfect, also the line of action of the lever hoist must coincide with the jaw bore centre.

The present method to accomplish this is to place the jaw on the wooden blocks as shown in the figure below.

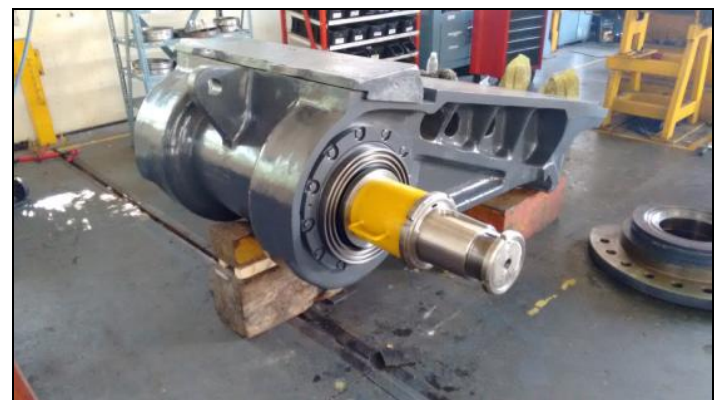

Fig 1.1 Jaw Placed on the Wooden Blocks

A wooden wedge is placed under the circular surface of the jaw to achieve the variable height occurring due change in the surface texture as the swing jaw is a casted part as well as the different range of the products viz. CJ211, 409 and 411.
The wedge takes care of the height while the horizontal alignment of the Swing Jaw Bore is checked by spirit level. If the bore is not perfectly aligned with reference to the ground it causes problem during the assembly, hence a jack is placed beneath it to resolve it as shown in the figures below.

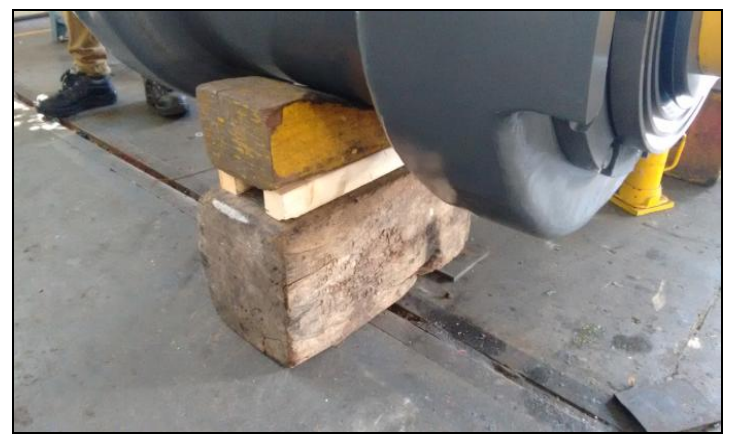

Fig 1.2 Wedge Placed beneath the Jaw

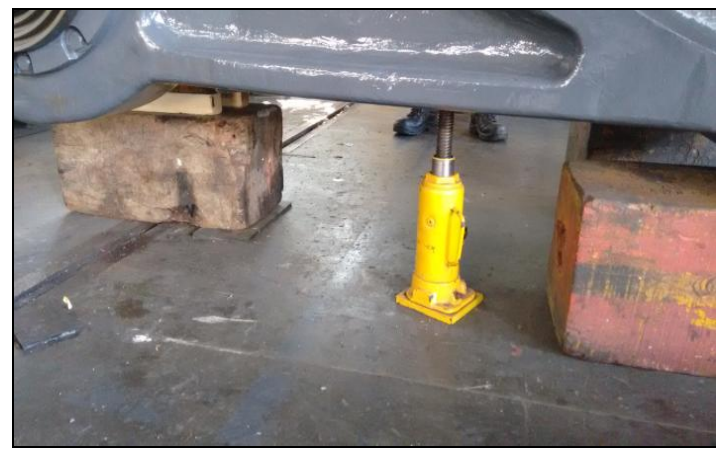

Fig 1.3 Jack used to align the Jaw bore 
When all this as completed then the further assembly procedure is carried out as follows:

1. Lift the Shaft using Belt and align its centre with the jaw bore centre.

2. Attach lever hoist chain to the eye bolt fitted in the shaft.

3. Push the shaft inside the Jaw bore and pull it from the other side by lever hoist simultaneously.

4. While inserting the first bearing, make sure that the outer race of bearing is perfectly aligned with the jaw bore for easy fitment of bearing in shaft. When it is done rest the shaft on the wooden block.

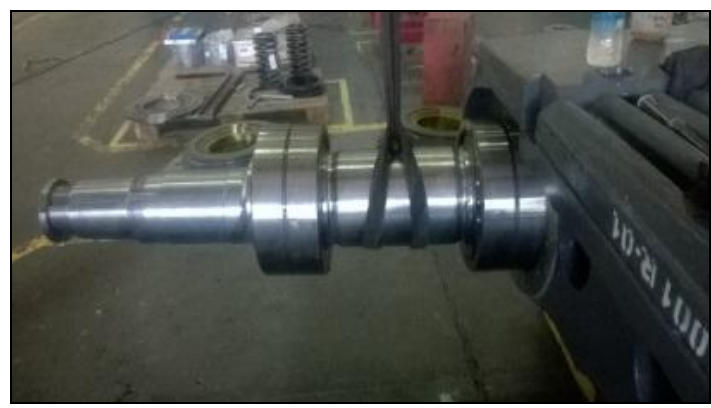

Fig 1.4 Shaft Assembly with Jaw

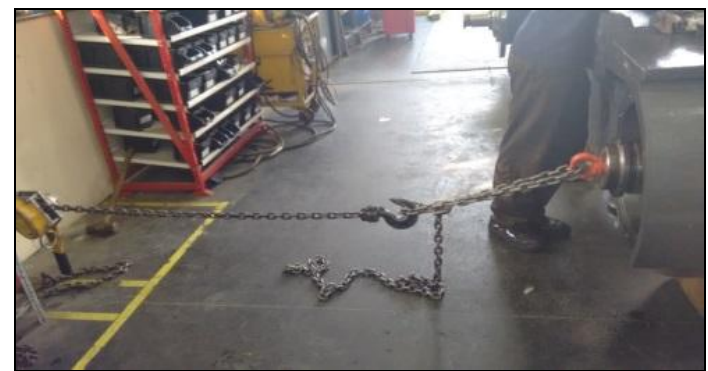

Fig 1.5 Pull the Shaft through guide side by lever hoist

Hence the preparations made before actually assembling the shaft with jaw are tedious and time consuming, but are essential non value adding activities. They also induce more fatigue on the production technologist working on the job.

\section{LITRATURE SURVEY}

Design and Development of Fixture for eccentric shaft: A Review

This paper shows a fixture design system of eccentric shaft for ginning machine. Fixture is required in various industries according to their needs. Designer design fixture according to dimension parameterized by industry to get their production tar gate. In old system manufacturing process performing operation on eccentric shaft is delicate. So gripping a work piece in required position during a manufacturing operation fixture is very necessary and vital. Because the shaft is eccentric so for this need of manufacturing process Designer design proper fixture for eccentric shaft. Fixtures lowers operation time and up bring productivity and apex quality of operation is possible.

\section{Fixture designers support expert system and concurrent engineering}

Researcher shows the main outlines of their process, that fixture design support system is developed on the basis of an expert system body. Researcher gives idea of how the use of that kind of tool is determinant factor for reactivity in the fixture design protocols in concurrent engineering. The paper aim for the development of fixture designer's support. Researcher present a outlining of the design method and expression of the trade norms in the expert system formalism. Researcher has developed formulating industrial expertise SEACMU (System Expert d'Aide il la Conception des Montages d'Usinage for expert system for final design). That is a fixture designers' support expert system. SEACMU is based on a adapted part modeling to the fixture design.

\section{PROBLEM STATEMENT}

The swing jaw of all the three models of Jaw Crusher is assembled on three wooden blocks. As there are three different size models it becomes difficult to adjust the height of wooden blocks as per the model. It is a time consuming process as the swing jaw weighs 8.1 Tonne and requires continuous help of overhead crane and extra manpower.

Problem also arises because of the material of the swing jaw, is casted and every single piece of swing jaw has different irregular outer surface which tends to improper resting on the wooden blocks.

During assembly of shaft into the bore of the swing jaw, due to improper resting of swing jaw, another problem arises i.e. misalignment of line of action and center bore.

When the shaft is pulled by lever hoist, because of no constraint in direction of pull the swing jaw tends to move along with the shaft in the direction of force applied.

Safety is another major challenge in the assembly process as the blocks are a type of temporary support, constant threat to the production technologist is there.

In order to minimize the problems hydraulic jacks are also used for vertical height adjustment and horizontal bore alignment and overhead crane is in continuous use which increases the material, manpower and time requirement. 
Use of conventional support like wooden blocks, hydraulic lift and extensive use of overhead crane makes the work procedure more tedious and ergonomically it is not right procedure as it creates fatigue and affects manpower's health adversely.

\section{METHODOLOGY}

This phase of the fixture-design process requires the most creativity. A typical work piece can be located and clamped several different ways. The natural tendency is to think of one solution, then develop and refine it while blocking out other, perhaps better solutions.

The above problem can have solution as below

1. Wedge Operated Mechanically by using screw and nut mechanism

2. Two hydraulic jacks used to lift the rear end of the jaw to required height and degree

3. Two Screw Jacks used to lift the jaw.

From the above three the first option of mechanical wedge can take care of height adjustment of the jaw, but no the horizontal alignment.

The hydraulic jack system cannot be used as oil spills from the system will cause slippery shop surfaces as well as raises the fire hazards as during assembly process there may be need of welding and gas cutting during rejection and rework.

This leaves only the last option of having two screw jacks in conjunction with level sensors beneath the jaw bore two lift it such that require height is achieved and the jaw bore gets perfectly aligned.

\subsection{Important Factors While Designing Fixture}

Designing and fixtures depends upon so many factors. These factors are analysed to get design inputs for jigs and fixtures. The list of such factors is mentioned below:

a. Study of Workpiece and finished component size and geometry.

b. Type and capacity of the machine, its extent of automation.

c. Provision of locating devices in the machine.

d. Available clamping arrangements in the machine.

e. Available aligning devices, their accuracy.

f. Evaluation of variability in the performance results of the machine.

g. Rigidity and of the machine under consideration.

h. Required level of the accuracy in the work and quality to be produced.

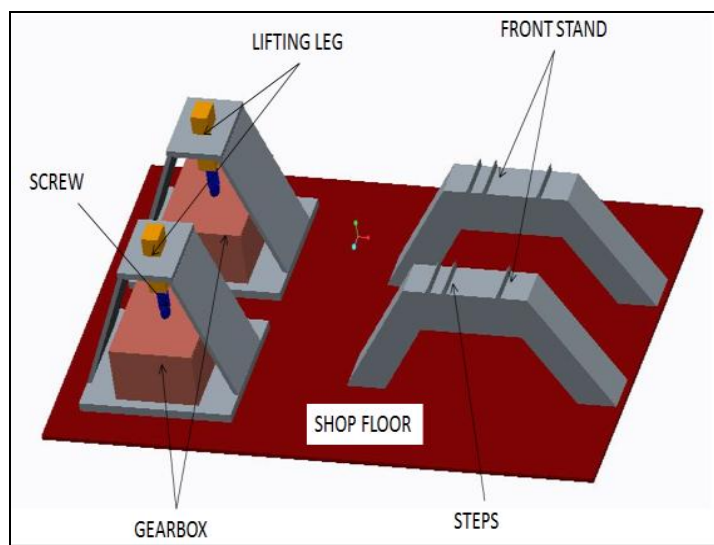

Fig 4.1 Setup of the Fixture

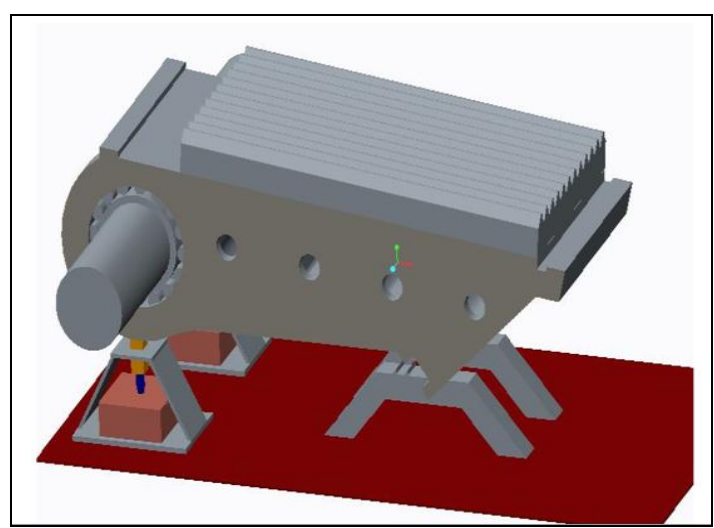

Fig 4.2 Setup while assembly

\section{Analytical calculation: \\ Design Power}

Screw

Material: Alloy steel,

Dc $=23 \mathrm{~mm}$

Nominal diameter $=26 \mathrm{~mm}$

Major diameter $=26 \mathrm{~mm}$

Length of the screw $=100 \mathrm{~mm}$

Design of Nut

Nut diameter $=26.5$

$\mathrm{P}=2 \mathrm{~mm}$

$\mathrm{Dm}==25 \mathrm{~mm}$

Worm \& Worm gear design

OD of worm $=$ Dow $=37$

$\mathrm{Dg}=78 \mathrm{~mm}$

Throat diameter $=83.99$

Face width $=b=30 \mathrm{~mm}$

\section{Worm Gear}

Speed $=1750$

Velocity ratio $=26$

No of start $=1$

No of teeth $=26$

Standard module $=3 \mathrm{~mm}$

Centre distance $=43.44 \mathrm{~mm}$

Diameter of worm $=32.21$

Face length $=70 \mathrm{~mm}$

Gear pair dimensions

Pinion 
Module $(\mathrm{m})=5$

No of Teeth $=12$

P.C.D $=60$

Face Width $=50$

Shaft Size $=25$

Key Size $=8$ X7X60

Gear

Module $(\mathrm{m})=5$

No Of Teeth $=42$

P.C.D $=210$

Face Width $=50$

Shaft Size $=35$

Key Size $=10$ X8X60

Analysis on software:

\section{ANALYSIS REAR END ASSEMBLY FRAME}

In any analysis software to give accurate results it is necessary that the constraints and the load application must be as per actual conditions on the system. The analysis of the rear end frame is as shown in the fig below

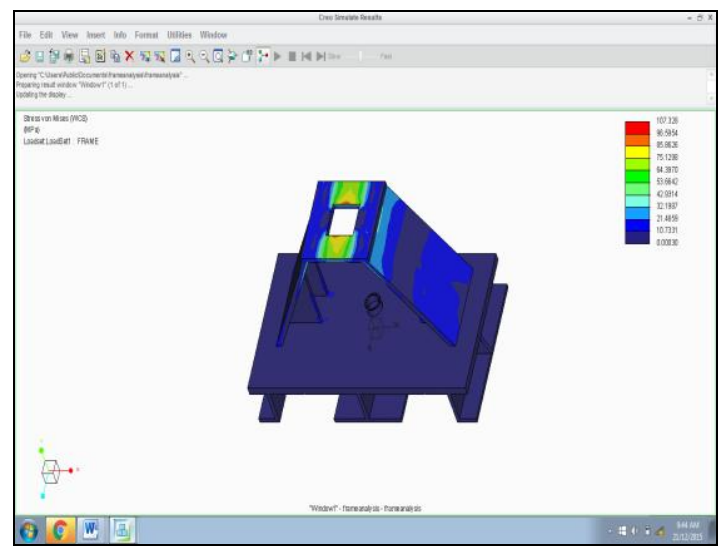

Fig 5.1 Load analysis

As the maximum stress induced is $107.38 \mathrm{Mpa}$ on the top plate which is less than allowable stress hence the design is safe.

\subsection{Jackleg Assembly}

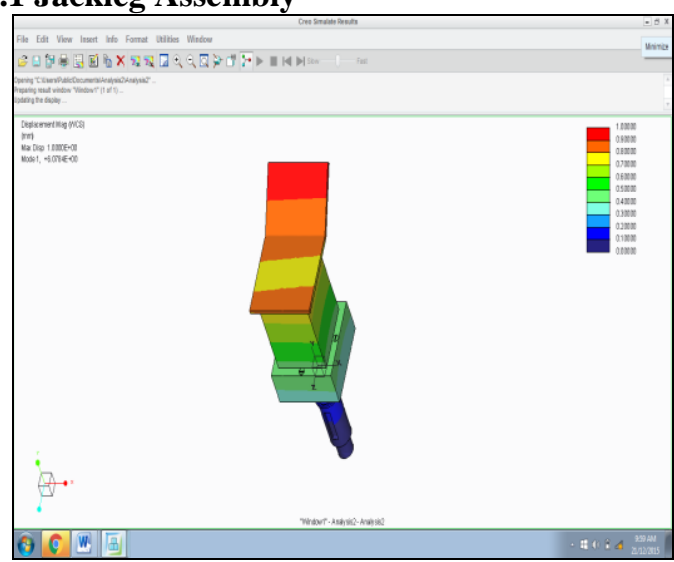

Fig 5.2 Buckling Load analysis

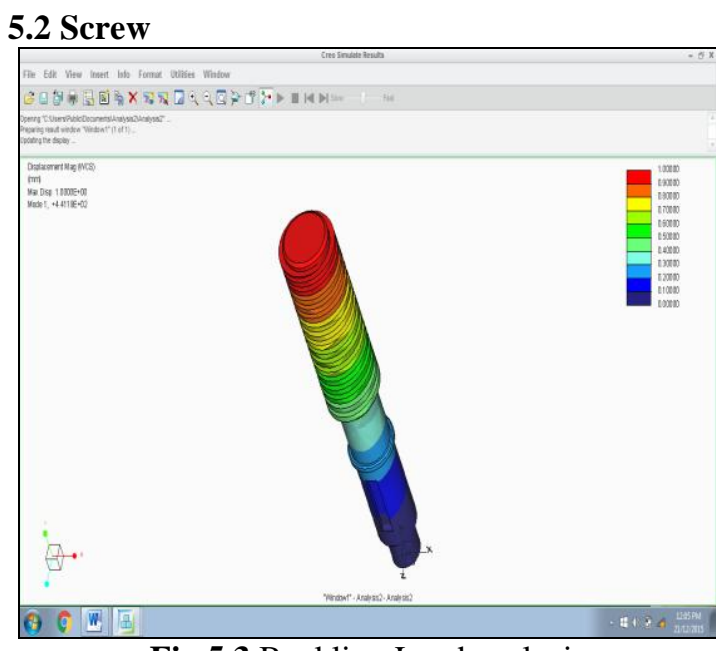

Fig 5.3 Buckling Load analysis

VI. WORKING MODEL

Gearbox Drawing

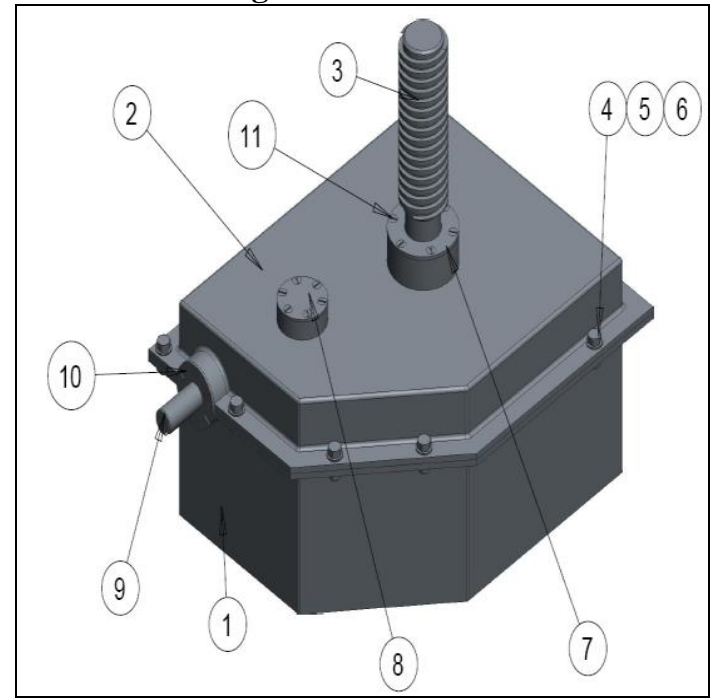

Fig 6.1 Gearbox Automated system

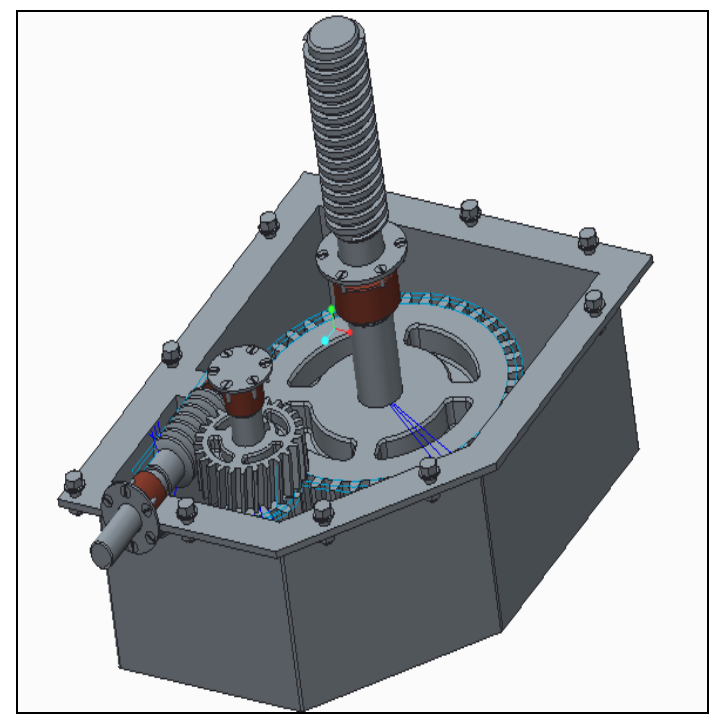

Fig 6.2 Gearbox details 


\subsection{Design Of Control System -}

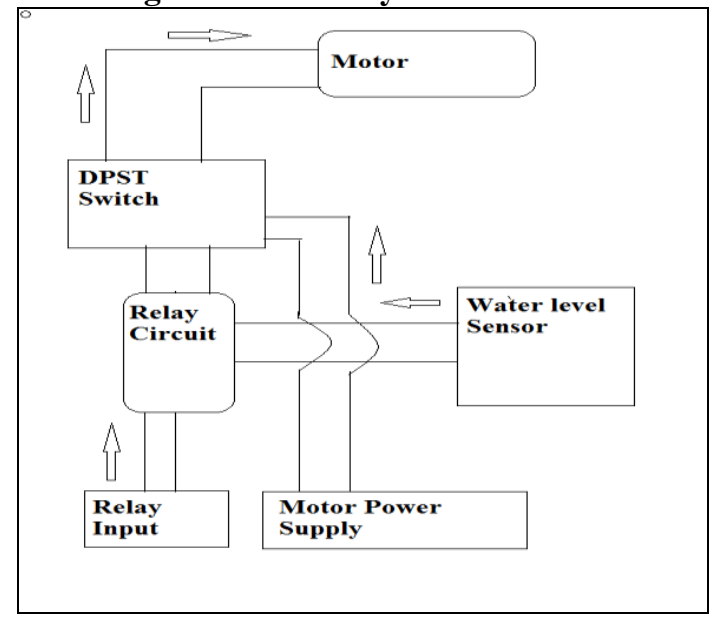

Fig 5.1 Block Diagram of electrical Circuit

\subsection{Motor-}

We have output power requirement of 100 $\mathrm{W}$ from prime mover to rotate the input worm at desirable speed and rated torque. So to met this requirement we decided to use $0.5 \mathrm{HP}$ (i.e. $373 \mathrm{~W}$ ) DC motor for this specific application.

Specification-

- Volts- 12 , Amps- 45

- $0.15-0.5 \mathrm{HP}, 0.1-0.4 \mathrm{KW}$

- Shaft Diameter: 0.625" - $15.9 \mathrm{~mm}$

- Face Mount in Any of the Direction

- Operates in Both two Directions

- All Ball Bearing Construction

- Brush Life 3,000 Hrs Minimum

- Ambient Temp 40 degrees C

- Insulation Class

\subsection{DPST Switch- (Double pole single throw)}

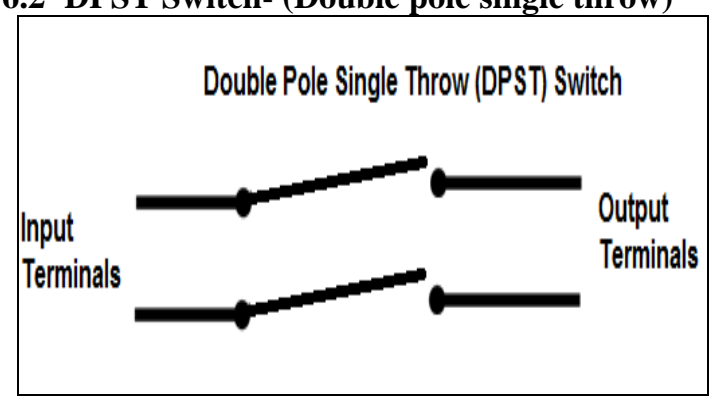

Fig 6.2.1 DPST Switch

Each terminals of a double pole single switch can ei be in the (closed) or in the off (open) condition. A Double Pole Single Switch has a lot of versatility or the variation being that it accepts 2 inputs, which makes it able to drive 2 different outputs in a circuit. . It drives depends on the circuit design and what the circuit is intended to do. But DPST have enormous applications in circuits. Reasons for using the DPST switch- a. Manual operation of the motors in case of failure of the sensors

b. To move the fixture up \& down as per the operators requirements

c. To control speed \& direction of rotation of the motor output shaft

\section{DESIGN OF MANUAL SYSTEM 7.1 Manual Gearbox}

The Manual system consist only screw of gear box arrangement without having motor as the prime mover. This will make the system less complicated and also reduce the cost of the motor.

Easier way is that to operate the screw directly with the hand lever, but according to the ergonomic study the max Grip force applied by an average human being is $100 \mathrm{~N}$ while we need the a Torque of $250 \mathrm{Nm}$ approx. to lift the jaw.

As we know that

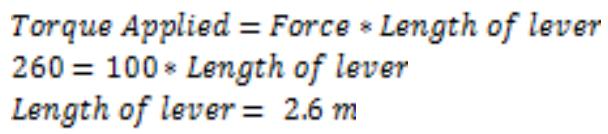

As it is not feasible to have such a long lever there is need of reduction gearbox as well as we have to transmit the torque at right angles to lift the load vertically, hence, it is convenient to use the worm and worm wheel drive.

The worm gears are widely used for transmitting power at high velocity ratios between non-intersecting shafts that are generally, but not necessarily, at right angles. It can give velocity ratios as high as 300:1 or more in a single step in a minimum of space, but it has a lower efficiency.

As the worm and worm designed earlier in the above gearbox is compatible with the manual design it will have of 26 , calculating the torque applied on worm

Torque Applied $=$ Torque aplied on worm $*$ gear ratio

$260=$ Torque aplied on worm $* 26$

Torque aplied on worm $=10 \mathrm{Nmm}$

Now the length of lever

Torque Applied = Force $*$ Length of lever

$10=100 *$ Length of lever

Length of lever $=0.1 \mathrm{~m}$

Which means the technologist can use a spanner of $100 \mathrm{~mm}$ length to operate the screw. We can develop a feature of bolt head on the worm shaft so that it can also be operated using impact wrench. As there are same axial loading conditions the bearings and bearing covers selected are same as that of automated gearbox. The detailed structure of the gearbox designed is as shown in the figure below 


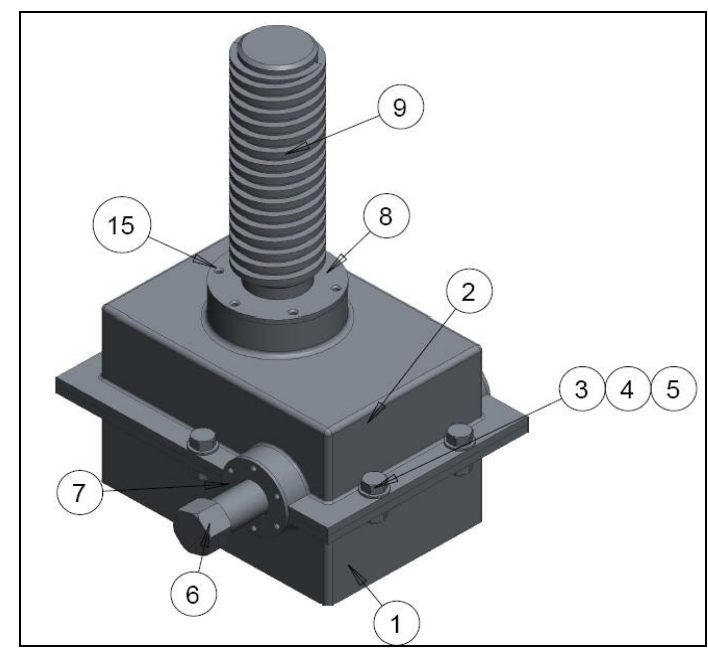

Fig 7.1 Gearbox for manual system

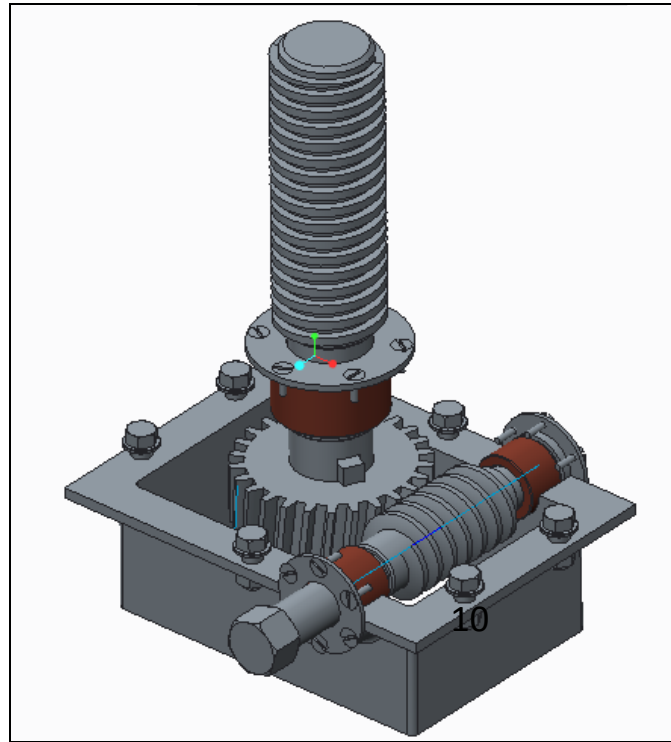

Fig 7.2 Gearbox details

\section{CONCLUSION}

A set up to aligning the bore and pulling center line Developed. Based on assembly of the bearings done Jaw crusher which enables the easy assembly increased safety and also reduces the chances of the premature bearing failure because of pulling shock load. Results of these fixture implementations are there will be lot of time saving along with increased life of bearing as misalignment in spherical roller bearing is not there. Also earlier this is very critical operation so skilled manpower and continue use of crane required which is also eliminated the next stage of the project is to calculate the pulling force of the bearing in jaw according to required fit type and pulling withy sensor which compare the force required actual so there are no chances of the loose and tight fit of bearing in jaw and if jaw bore size is within limit then only the bearing assembly will be done.

\section{ACKNOWLEDGMENT}

We take immense pleasure in thanking our college management for having permitted us to carry out this project work. Words are inadequate in offering our thanks to our respected co-operation in carrying out project work in the starting phase of the project like requirement analysis and literature survey. We also express our at most gratitude to Dr. K. B. Kale Head of department of Computer Engineering, for this valuable co-operation in selecting the project topic and guiding us stepwise ahead. Inspiration and guidance are invaluable in every aspect of life, especially in field of education, which we have received from our respected project guide Dr. R. R. Navtar who has helped a lot In first two phase of project like topic selection then information gathering and guide us to throughout the project work and gave earnest co-operation whenever required. We would like to express sincere gratitude towards him. At last, we would like to take this opportunity to convey thanks to all my staff members, who directly or indirectly encouraged and helped us project work. Finally yet importantly, we would like to express heartfelt thanks to our beloved parents for their blessings, our friends/classmates for their and helps and wishes.

\section{REFERENCES}

[1]. Meridith Grimsley and Birmingham, Slide assembly fixture for rear hub assembly, United States patent, Patent No. 7225516, (2007).

[2]. Frank M Prucha and Birmingham, Ring assembly fixture, United States patent, Patent No. 2865091, (1958).

[3]. William Hunter, Upland, Gerard A Naab and Morton, Assembly and test fixture, United States patent, Patent No. 160394, (1964).

[4]. Shalette Farmer, Instrument panel assembly fixture, United States patent, Patent No. 2010/00450651A1, (2010).

[5]. John B. Gray 3 and William R. Yeich, Assembly Fixture, United States patent, Patent No. 2801329, (1957).

[6]. Arthur Richard Baker Jr., Fixture for assembling electronic circuit modules, United States patent, Patent No.5732462, (1998). 